\title{
Dramatic change in public attitudes towards vaccination during the 2009 influenza A(H1N1) pandemic in France
}

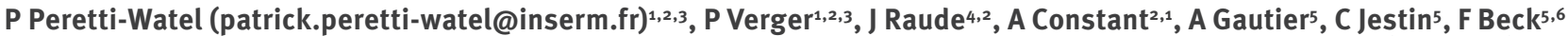

1. INSERM, UMR912 Economics and Social Sciences Applied to Health and Analysis of Medical Information (SESSTIM), Marseille, France

2. Aix Marseille University, UMR_S912, IRD, Marseille, France

3. ORS PACA, Southeastern Health Regional Observatory, Marseille, France

4. Department of Social and Behavioural Sciences, EHESP Rennes, Sorbonne Paris Cité, France

5. National Institute for Prevention and Health Education (INPES), St Denis Cedex, France

6. Cermes3 - Equipe Cesames (Research Centre on Medicine, Sciences, Health, Mental health and Society), University Paris Descartes, Sorbonne Paris Cité/CNRS UMR 8211/Inserm U988/EHESS), Paris Cedex 06, France

Peretti-Watel P, Verger P, Raude J, Constant A, Gautier A, Jestin C, Beck F. Dramatic change in public attitudes towards vaccination during the 2009 influenza A(H1N1) pandemic in France. Euro Surveill. 2013;18(44):pii=20623. Available online: http://www.eurosurveillance.org/ViewArticle.aspx?Articleld=20623

Article submitted on 14 January 2013 / published on 31 October 2013

We investigated the potential impact of the 2009 influenza $\mathrm{A}\left(\mathrm{H}_{1} \mathrm{~N}_{1}\right)$ pandemic on attitudes towards vaccination among people aged 18 to 75 years and living in metropolitan France. We used data from three national telephone surveys conducted on representative samples in 2000, 2005 and $2010(n=12,256$, $n=23,931, n=8,573$ respectively). In France, unfavourable attitudes towards vaccination in general dramatically increased from $8.5 \%$ in 2000 and $9.6 \%$ in 2005 to $38.2 \%$ in 2010 . In 2010 , among respondents who held unfavourable attitudes towards vaccination, 50\% mentioned specifically their opposition to the influenza $A\left(\mathrm{H}_{1} \mathrm{~N}_{1}\right)$ vaccine. The sociodemographic profile associated with these attitudes also changed greatly. In particular, unfavourable attitudes towards vaccination in general became significantly more frequent among less educated people in 2010. These attitudes were also correlated with vaccination behaviours. For example, parents who were unfavourable towards vaccination in general were more likely to report that they had at least one child who did not get the measlesmumps-rubella vaccine. As this shift in attitude may have a significant impact on future vaccination coverage, health authorities should urgently address the vaccine confidence gap.

\section{Introduction}

Public concern about vaccine safety is as old as vaccines themselves $[1,2]$. Nevertheless, many public health experts consider that one of the greatest challenges currently facing vaccinology is the ongoing decline of public confidence in vaccines [3-6]. Such decline is illustrated by the so-called revival of antivaccination movements that may compromise immunisation programmes [7-9]. Another illustration is the suboptimum measles-mumps-rubella (MMR) vaccination coverage observed in many European countries, which has recently caused several measles outbreaks, especially in France [10-12]. This vaccine confidence gap is also illustrated by controversies surrounding specific vaccines during the last decades, including MMR vaccine in the United Kingdom, hepatitis $B$ vaccine in France, and not least the 2009 influenza $A\left(\mathrm{H}_{1} \mathrm{~N}_{1}\right)$ vaccine [5].

A number of studies have been carried out to investigate factors associated with attitudes and behaviours towards the 2009 influenza $A\left(\mathrm{H}_{1} \mathrm{~N}_{1}\right)$ vaccine. Many of them found that the willingness to accept this vaccine was significantly associated with respondents' sociodemographic background (gender, age, household's composition, socioeconomic status), as well as with prior vaccination attitudes and behaviours, and especially seasonal influenza vaccination uptake [13-17]. Conversely, only a few studies have investigated the potential impact of the 2009 influenza $A\left(\mathrm{H}_{1} \mathrm{~N}_{1}\right)$ pandemic on public attitudes and behaviours towards vaccination in general [18-19].

In the present study, we investigated the potential impact of the 2009 influenza $A\left(\mathrm{H}_{1} \mathrm{~N}_{1}\right)$ pandemic on attitudes towards vaccination in general among people living in metropolitan France. In particular, we aimed at testing the following three hypotheses: (i) we expect a growing proportion of French citizens to express unfavourable attitudes towards vaccination in general during the 2009 influenza $A\left(\mathrm{H}_{1} \mathrm{~N}_{1}\right)$ episode; (ii) as a growing number of French citizens oppose vaccination, their sociodemographic profile should change; (iii) such opposition should be a significant predictor of vaccination behaviours. We used data from three national surveys conducted by the French National Institute for Prevention and Health Education (INPES) in 2000, 2005 and 2010. In order to test these 
hypotheses, we first compared the French population's attitudes towards vaccination across the three surveys, from 2000 to 2010. As the data collection process took several months for the last survey, from October 2009 to June 2010, we also had the opportunity to observe how these attitudes changed during the influenza $A\left(\mathrm{H}_{1} \mathrm{~N}_{1}\right)$ pandemic. Secondly, we investigated the sociodemographic factors associated with attitudes towards vaccination in general and compared them across the three surveys. Thirdly, we examined the relationship between attitudes towards vaccination and self-reported vaccination behaviours.

\section{Methods}

\section{Design and samples}

We used data from the last three waves (2000, 2005, 2010) of the 'Health Barometer', a telephone survey on health perceptions, knowledge, attitudes and behaviours targeted at the general population and conducted by the INPES. Each wave was carried out on a representative random sample of the population aged 12 to 75 years ( 15 to 85 years in 2010) living in continental France by use of a computer-assisted telephone interview (CATI) system.

Design and protocol were identical for the three surveys and have been approved by the French Commission on Individual Data Protection and Public Liberties (CNIL). They were based on a two-stage random sample of French-speaking people. Residents of collective dwellings, hospitals and institutions were excluded from the target population. Private households with landline telephones were included in the sample (phone numbers were randomly generated, in order to include people with confidential numbers), as well as people owning only mobile phones. The first sampling step was household selection (by phone number), then an eligible subject was randomly selected to answer the questions, using the next-birthday method in 2000 and 2005 (the interviewer asked which member of the household of eligible age had their birthday coming up next and interviewed that person), and the Kish method in 2010 (the interviewer asked for the first names of all household members and for their birthdays, then selected the respondent whose birthday was most recent). All collected data were anonymised and self-reported. The study protocol included a formal request to participate, sent by postal mail, explaining the objectives of the study. This letter was sent before the first telephone call (or after for subjects with confidential numbers whose addresses were initially unknown).

\section{Data collected}

The sample sizes reached $n=13,685$ in 2000, $n=26,672$ in 2005 and $n=9,761$ in 2010, with similar cooperation rates $(64 \%, 58 \%$ and $61 \%$, respectively). We restricted the analysis to respondents aged 18 to 75 , corresponding to $n=12,256$ in $2000, n=23,931$ in $2005, n=8,573$ in 2010.
Respondents were asked about their attitude towards vaccination in general ('very favourable', 'somewhat favourable', 'somewhat unfavourable', 'very unfavourable'). They were also asked whether or not they were unfavourable towards certain vaccines in particular, and if so, to which ones (with an open-ended question and multiple responses allowed). Regarding vaccination behaviour, respondents with children aged one to 15 years were asked in the three surveys if at least one of the children had not been vaccinated with the combined MMR vaccine. In 2005 and 2010, participants were also requested to report their own general immunisation status (up-to-date or not). Finally, in 2010 only, they were asked whether or not they had been vaccinated against seasonal influenza in 2008.

The questionnaire collected data on respondents' sociodemographic background: gender, age, educational level, household composition and income. For each respondent, we computed the equivalised household income (EHI). EHI involves a weighting scale that enables analysis of the relative well-being of households of different size and composition. We counted 1 point for the first adult in the household, 0.5 points for each additional person aged 15 years and older, and 0.3 points for each child younger than 15 years. EHI is computed by dividing total household income by the sum of points allocated to the household members.

\section{Statistical analysis}

Data were weighted with respect to the inclusion probability. They were also adjusted to distributions in the French population according to gender, age, educational level, geographical region and urbanisation level. All statistical analyses were performed using the weighted data.

Firstly, we compared respondents' attitudes towards vaccination in general across the three waves of the Health Barometer, as well as their responses to the open question (people were asked to indicate, unprompted, toward which vaccines they were unfavourable). Concerning the 2010 wave, as data collection lasted from October 2009 to June 2010, we examined how the attitudes towards vaccination in general varied during this period. To do so, we collapsed the four response items into a binary outcome ('somewhat' or 'very' unfavourable, versus 'somewhat' or 'very' favourable and no response). As the sociodemographic structure of the monthly subsamples differed, we took this into account to make each month comparable to the others (with a weighting procedure based on gender and age distributions). The size of the monthly subsamples was quite small for October $(n=272)$, June $(n=279)$ and May $(n=674)$, but above $n=1,000$ for the other months. For each month we computed the proportion of respondents who were unfavourable towards vaccination in general, and the corresponding $95 \%$ confidence intervals. We used the Pearson's chi-square test for bivariate analyses and Wald's chi-square for logistic 


\section{FIGURE 1}

Attitudes towards vaccination in general in the population aged 18-75 years, INPES surveys, France, 2000, 2005, 2010

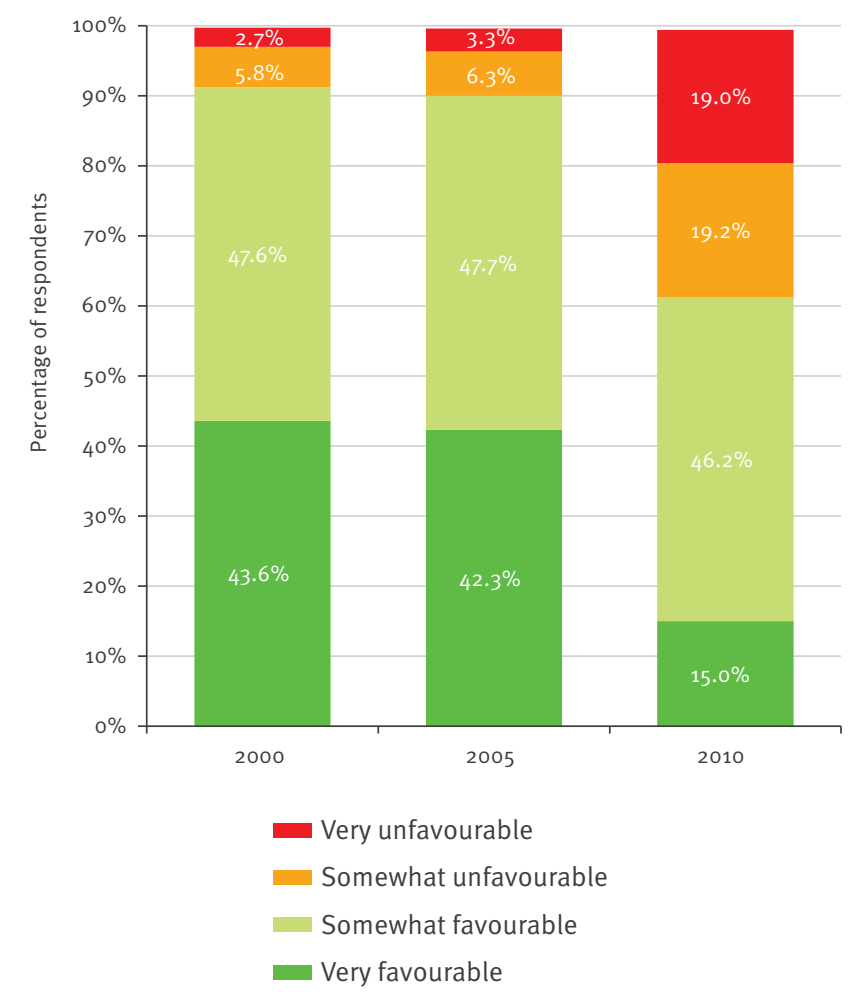

INPES: French National Institute for Prevention and Health Education.

Percentages do not add up to $100 \%$ as a few people refused to answer this question or answered 'don't know'

regressions to assess the statistical significance of observed variations.

Secondly, for each wave separately, we investigated the sociodemographic factors associated with attitudes towards vaccination in general (using the binary outcome). We performed bivariate analyses and multivariate analyses with logistic regression models. The following covariates were introduced into the models: gender, age, educational level, EHI and presence of at least one child aged under the age of four years in the household. For each of them, we computed adjusted odds ratios.

Finally, for each wave separately, we examined the relationship between attitudes towards vaccination in general and vaccination behaviours (with logistic regressions taking into account gender, age, educational level, $\mathrm{EHI}$ and presence of at least one child aged under the age of four years in the household as potential confounding factors).

\section{Results}

Attitudes towards vaccination

from 2000 to 2010

Figure 1 displays reported attitudes towards vaccination in general in 2000, 2005 and 2010. Non-responses were very rare for the three waves ( $<1 \%)$. The distributions of attitudes towards vaccination in general were quasi identical in 2000 and 2005. Unfavourable attitudes were reported by $8.5 \%$ of respondents in 2000 and $9.6 \%$ in 2005 , but this proportion dramatically increased in 2010 , reaching $38.2 \%$.

Among respondents who stated that they were unfavourable towards vaccination in general, in $2000,22 \%$ reported that they were unfavourable towards all vaccines (16\% in 2005), 24\% mentioned specifically their opposition to the seasonal influenza vaccine $(20 \%$ in 2005), another $24 \%$ mentioned the hepatitis $B$ vaccine (37\% in 2005), $9 \%$ the MMR vaccine ( $8 \%$ in 2005) and another $9 \%$ the tuberculosis vaccine ( $9 \%$ in 2005). In 2010, all these proportions decreased sharply: among respondents who were unfavourable towards vaccination in general, $5 \%$ opposed all vaccines, $11 \%$ mentioned the seasonal influenza vaccine, $12 \%$ mentioned the hepatitis B vaccine, $2 \%$ the MMR and $2 \%$ the tuberculosis vaccine. Moreover, among those opposing vaccination in general, $50 \%$ mentioned spontaneously their opposition to specifically the influenza $A\left(\mathrm{H}_{1} \mathrm{~N}_{1}\right)$ vaccine.

Looking more closely at data collected from October 2009 to June 2010, it appeared that the proportion of respondents who reported being unfavourable towards vaccination in general varied significantly during this period ( $p<0.001$ ) (Figure 2$): 31 \%$ of respondents opposed vaccination in general in October 2009, this proportion rose to $40-41 \%$ in December-January and began to decline only after March 2010 (31\% in June).

\section{Sociodemographic factors associated with attitudes towards vaccination in general} The sociodemographic factors associated with unfavourable attitudes towards vaccination in general were quite similar in 2000 and 2005 (Table 1). Female respondents were more likely to express such attitudes (odds ratio (OR): 1.27 in 2000, 1.25 in 2005), as well as older respondents (OR for those aged 65 to 75 years: 3.32 in 2000, 3.25 in 2005, with 18 to 24 year-olds as the reference category). In multivariate analysis, for the surveys conducted in 2000 and 2005 , educational level and presence of children under the age of four years in the household were not significant predictors of attitudes towards vaccination. Finally, concerning EHI, we observed a slightly significant ( $p<0.05)$ effect in 2000 (OR: 0.79 for the highest income level versus the lowest one), which became non-significant in 2005 (OR: 0.92).

The results were quite different in 2010. The gender effect reversed, as female respondents became less 
Percentage of 18-75 year-olds who reported being 'very' or 'somewhat' unfavourable towards vaccination in general, INPES survey, France, October 2009-June 2010 (n=8,573)

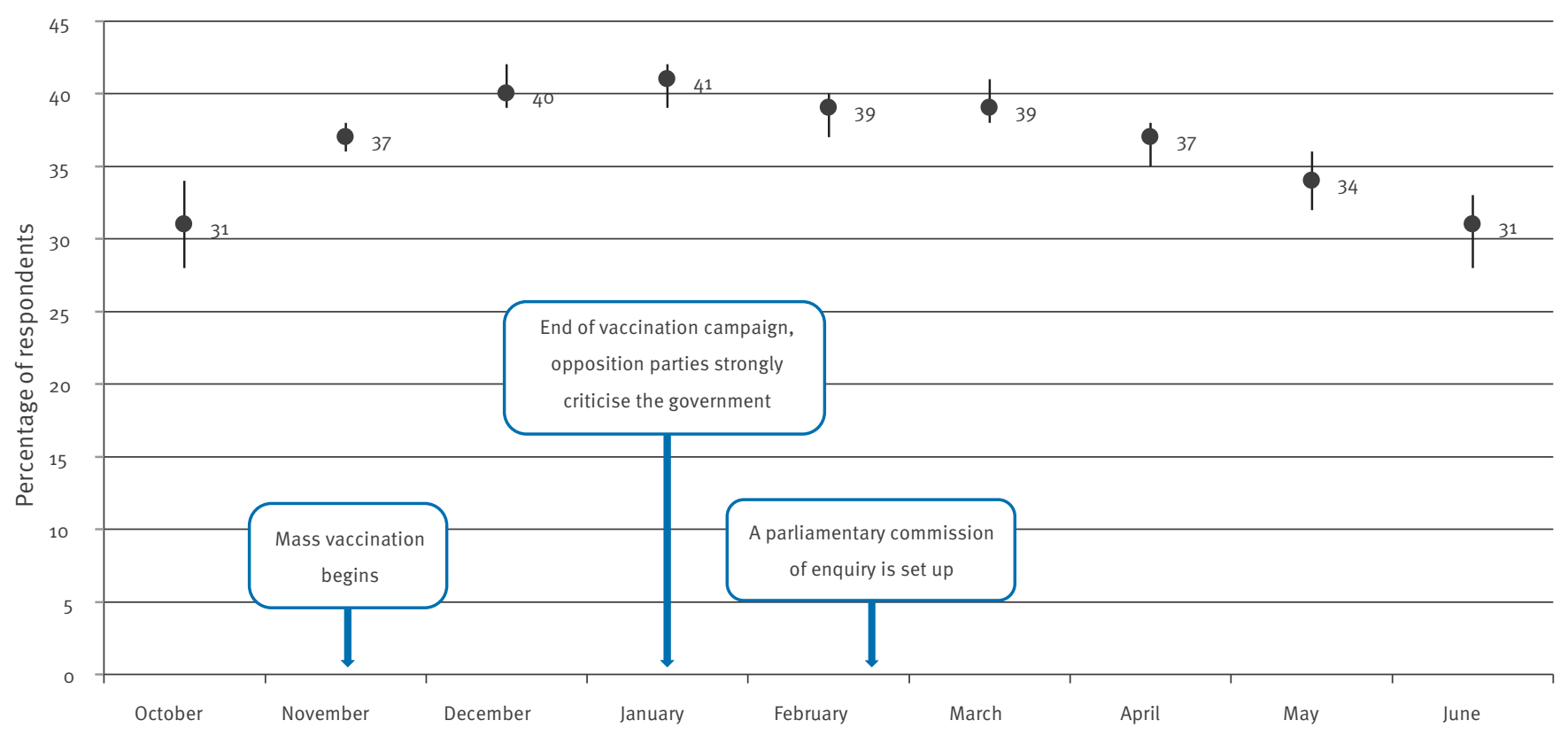

INPES: French National Institute for Prevention and Health Education. $95 \%$ confidence intervals are represented by vertical segments.

likely to oppose vaccination in general (OR: 0.88). The age effect also changed, as opposition to vaccination proved more prevalent among respondents aged 50 to 64 years (instead of those aged 65 to 75 years in 2000 and 2005). Moreover, educational level and presence of children under the age of four years in the household became significant predictors of attitudes towards vaccination in general: the propensity to express unfavourable attitudes decreased as the educational level rose, and this propensity was also lower among respondents who had at least one child aged under the age of four years in their household. Finally, the income effect did not change: in 2010 as in 2000 , wealthier people were less likely to oppose vaccination in general.

\section{Attitudes towards vaccination}

\section{and vaccination behaviours}

In all three Health Barometers, among respondents who had at least one child aged one to 15 years in their household, attitudes towards vaccination in general were significantly correlated with their children's) immunisation status regarding the MMR vaccine (Table 2): those who endorsed unfavourable attitudes towards vaccination in general were more likely to report that they had at least one child who had not received the MMR vaccine (OR: 4.20 in 2000, 5.95 in 2005, 1.53 in 2010). In 2005 and 2010, respondents who were unfavourable towards vaccination in general were less likely to state that their vaccinations were up to date (OR: 0.27 and 0.41 respectively). Finally, in 2010, among respondents aged 65 years and older (French health authorities strongly recommend seasonal influenza vaccine for this age category), these unfavourable attitudes were negatively associated with vaccination against seasonal influenza in 2008 (OR: 0.13).

\section{Discussion}

\section{Limits of the study}

We have to acknowledge several limitations of the present study. First, our data might be biased, since a significant minority of contacted households/people refused to participate. These refusal rates were quite low, however, in comparison with similar telephone surveys, and we have no particular reason to suspect that vaccination attitudes and behaviours may have been correlated with refusal, as the letter announcing the survey did not detail the topics to be investigated. Secondly, our study shares the usual limitations of retrospective surveys based on self-reporting, including recall bias and social desirability bias, especially for vaccination behaviours. Thirdly, we do not know when unfavourable attitudes towards vaccination started to increase, as no data were collected before October 
TABLE 1

Factors associated with unfavourable attitudes towards vaccination in general, INPES surveys, France 2000, 2005, 2010

\begin{tabular}{|c|c|c|c|c|c|c|}
\hline & \multicolumn{2}{|c|}{$2000(n=12,256)$} & \multicolumn{2}{|c|}{$2005(n=23,931)$} & \multicolumn{2}{|c|}{$2010(n=8,573)$} \\
\hline & Row \% & OR & Row \% & OR & Row \% & OR \\
\hline \multicolumn{7}{|l|}{ Gender } \\
\hline Male (ref.) & $7 \%$ & 1 & $9 \%$ & 1 & $39 \%$ & 1 \\
\hline Female & $10 \%$ \%** & $1.27^{\star \star \star}$ & $11 \%$ *** & $1.25^{* \star *}$ & $37 \% *$ & $0.88^{\text {ns }}$ \\
\hline \multicolumn{7}{|l|}{ Age (years) } \\
\hline $18-24$ (ref.) & $5 \%$ & 1 & $5 \%$ & 1 & $27 \%$ & 1 \\
\hline $25-34$ & $6 \%$ & $1.19^{\mathrm{ns}}$ & $8 \%$ & $1.81^{\star \star \star}$ & $32 \%$ & $1.49^{\star \star}$ \\
\hline $35-49$ & $8 \%$ & $1.68^{\star \star \star}$ & $9 \%$ & $2.01^{\star \star \star}$ & $36 \%$ & $1.54^{\star \star}$ \\
\hline $50-64$ & $10 \%$ & $2.22^{\star \star \star}$ & $11 \%$ & $2.47^{\star \star \star}$ & $48 \%$ & $2.45^{\star \star \star}$ \\
\hline $65-75$ & $14 \%$ \%** & $3.32^{* * *}$ & $14 \%$ *** & $3.25^{\star \star \star}$ & $43 \%$ \%** & $1.91^{\star \star *}$ \\
\hline \multicolumn{7}{|l|}{ Educational level } \\
\hline No diploma (ref.) & $11 \%$ & 1 & $11 \%$ & 1 & $48 \%$ & 1 \\
\hline Below high-school graduation & $9 \%$ & $0.84^{\mathrm{ns}}$ & $10 \%$ & $0.93^{\text {ns }}$ & $42 \%$ & $0.77^{\star}$ \\
\hline High-school, first university degree & $7 \%$ & $0.95^{\mathrm{ns}}$ & $8 \%$ & $0.94^{\mathrm{ns}}$ & $32 \%$ & $0.60^{* *}$ \\
\hline Three or four years completed at university & $10 \%$ & $1.28^{\mathrm{ns}}$ & $11 \%$ & $1.16^{\mathrm{ns}}$ & $28 \%$ & $0.49^{\star \star \star}$ \\
\hline More than four years completed at university & $6 \% * \star *$ & $0.78^{\mathrm{ns}}$ & 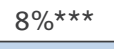 & $0.87^{\mathrm{ns}}$ & $23 \%$ *** & $0.37^{\star \star \star}$ \\
\hline \multicolumn{7}{|l|}{ Equivalised household income } \\
\hline$<900 € /$ month (ref.) & $9 \%$ & 1 & $10 \%$ & 1 & $40 \%$ & 1 \\
\hline $900-1,500 € /$ month & $9 \%$ & $0.97^{\text {ns }}$ & $9 \%$ & $0.90^{\text {ns }}$ & $42 \%$ & $1.06^{\text {ns }}$ \\
\hline$\geq 1,500 € /$ month & $7 \%$ & $0.79^{\star \star}$ & $9 \%$ & $0.92^{\mathrm{ns}}$ & $34 \%$ & $0.85^{\star}$ \\
\hline Don't know/refuse to answer & $10 \% *$ & $1.11^{\mathrm{ns}}$ & $11 \%^{\star}$ & $1.13^{\mathrm{ns}}$ & $39 \% * \star \star$ & $0.92^{\text {ns }}$ \\
\hline \multicolumn{7}{|l|}{ Children under four years in the household } \\
\hline None (ref.) & $9 \%$ & 1 & $10 \%$ & 1 & $40 \%$ & 1 \\
\hline At least one & $7 \% *$ & $1.13^{\mathrm{ns}}$ & $8 \% * \star \star$ & $0.89^{\mathrm{ns}}$ & $28 \% * \star \star$ & $0.72^{\star}$ \\
\hline
\end{tabular}

INPES: French National Institute for Prevention and Health Education; OR: adjusted odds ratio; Ref: reference category in logistic regression. *** statistically significant at p<0.001; ** statistically significant at p<0.01; * statistically significant at p $<0.05$; ns not significant (Pearson's chi-square test for bivariate analysis, Wald's chi-square for logistic regressions).

The Table shows row percentages and adjusted odds ratios.

\section{TABLE 2}

Adjusted odds ratios measuring the impact of attitudes towards vaccination in general on vaccination behaviours, INPES surveys, France, 2000, 2005, 2010

\begin{tabular}{|c|c|c|}
\hline Dependent variable & Year & $\begin{array}{c}\text { OR }[95 \% \mathrm{Cl}]^{\mathrm{a}} \\
\text { unfavourable versus favourable }\end{array}$ \\
\hline At least one child aged one to 15 years in the household did not get the MMR vaccine ${ }^{b}$ & $\begin{array}{l}2000 \\
2005 \\
2010\end{array}$ & $\begin{array}{l}4.20[3.09-5.71] \\
5.95[4.89-7.24] \\
1.53[1.14-2.06]\end{array}$ \\
\hline Respondent's immunisation status up to date & $\begin{array}{l}2005 \\
2010\end{array}$ & $\begin{array}{l}0.27[0.24-0.29] \\
0.41[0.36-0.46]\end{array}$ \\
\hline Respondent aged 65 years or older and vaccinated against seasonal influenza in 2008 & 2010 & $0.13[0.09-0.17]$ \\
\hline
\end{tabular}

$\mathrm{Cl}$ : confidence interval; EHI: equivalised household income; INPES: French National Institute for Prevention and Health Education; OR: adjusted odds ratio.

a Odds ratios adjusted to gender, age, education and EHI levels, and presence of children under the age of four years in the household in a logistic regression.

b Among the subsample of respondents who had at least one child aged one to 15 years in their household. 
2009. Finally, the comparison between data collected in 2000, 2005 and 2010 could have been biased since the corresponding sample sizes were quite heterogeneous. Such heterogeneity may induce lower levels of statistical significance for analyses conducted on the smaller samples (in this case the 2010 sample), but as the statistical relationships measured in 2010 were quite strong, we did not encounter this problem.

\section{Impact of the 2009 influenza $A(H 1 N 1)$}

pandemic on attitudes towards vaccination

Despite the third limitation mentioned above, our results strongly suggest that the 2009 influenza $\mathrm{A}\left(\mathrm{H}_{1} \mathrm{~N}_{1}\right)$ episode had a dramatic impact on attitudes towards vaccination in general, at least among the French (hypothesis (i) confirmed). Beyond the increase in negative attitudes observed in 2009 to 2010 , half of the respondents who endorsed these attitudes spontaneously mentioned their opposition to the influenza $\mathrm{A}\left(\mathrm{H}_{1} \mathrm{~N}_{1}\right)$ vaccine. These attitudes reached a peak in December and January, when French health authorities and the World Health Organization began to be sharply criticised in the French media for exaggerating the influenza $A\left(\mathrm{H}_{1} \mathrm{~N}_{1}\right)$ threat. This attitudinal shift illustrates the proposition that many people who accept vaccines could change their mind [5], and it supports the hypothesis that the 2009 influenza $A\left(\mathrm{H}_{1} \mathrm{~N}_{1}\right)$ episode may have undermined public confidence in health authorities and vaccination [20]. In France, concerns about vaccine safety started to get media attention in November, but the level of negative attitudes towards vaccination in general had already reached $33 \%$ in October. Nevertheless, controversies regarding the seriousness of the pandemic threat and the massive purchase of vaccine began in July 2009. Consequently, the 2009 influenza $A\left(\mathrm{H}_{1} \mathrm{~N}_{1}\right)$ episode certainly contributed to the increase in negative attitudes towards vaccination in general, but it may not be the only cause. Furthermore, it is not possible to assess at this stage how long such negative attitudes will last.

\section{Socioeconomic status and attitudes \\ towards vaccination}

The sociodemographic profile associated with unfavourable attitudes towards vaccination in general significantly changed in 2009/10 (hypothesis (ii) confirmed). The profile observed in 2009/10 also suggests a link between these attitudes and opposition to the influenza $A\left(\mathrm{H}_{1} \mathrm{~N}_{1}\right)$ vaccine. Indeed this profile was consistent with results from previous French studies that investigated factors associated with influenza $A\left(\mathrm{H}_{1} \mathrm{~N}_{1}\right)$ vaccine uptake or acceptance: Influenza $A\left(\mathrm{H}_{1} \mathrm{~N}_{1}\right)$ vaccination acceptance was found to be higher among more educated and wealthier people [21], its uptake was correlated with high educational level, high socioeconomic status and living in a household with a child under the age of five years [16].

In contrast, some previous studies found that highly educated parents were prone to refuse vaccination for their children [22-24]. However, these parents did not oppose vaccination in general, they rather want to balance the risks and benefits of each vaccination, and their hesitancy is often directed at specific vaccines $[25,26]$. More generally, studies on risk perceptions usually found that low socioeconomic status people are more sensitive to risks, especially for unfamiliar and controversial risks [27], and the 2009 influenza $A\left(\mathrm{H}_{1} \mathrm{~N}_{1}\right)$ episode may have contributed to shifting the perception of vaccine risks towards being more unfamiliar and controversial than they were perceived before. Of course, such change in risk perceptions may be temporary and reversible, at least partially, as suggested by the inverted ' $U$ ' shape in Figure 2.

Our results also suggest an increasing social differentiation of attitudes towards vaccination, as two usual markers of a low socioeconomic status, namely a low educational level and a low income level, became predictive of unfavourable attitudes in 2010. As trust in public health authorities is a key issue regarding vaccination acceptance in general and influenza $A\left(\mathrm{H}_{1} \mathrm{~N}_{1}\right)$ vaccination acceptance in particular $[4-6,21,28]$, such disparities may result from the social differentiation of trust in health authorities and the pharmaceutical industry. This hypothesis is supported by a number of previous studies. For example, a German study dealing with information-seeking behaviour during the 2009 influenza $A\left(\mathrm{H}_{1} \mathrm{~N}_{1}\right)$ pandemic found that people with lower education were much less likely to use information material from official authorities [29]. An American study also found that people belonging to ethnic minorities (who often have a lower socioeconomic status) were more likely to distrust influenza vaccination, and this belief was associated with lower vaccination rates [30]. More generally, a low socioeconomic status is frequently associated with mistrust of health authorities [31]. The social differentiation of confidence in health authorities and vaccination programmes could significantly contribute to health inequalities in infectious diseases, which are public health priority [32].

Attitudes towards vaccination

and vaccination behaviours

To our knowledge, only a few studies have investigated the potential impact of the 2009 influenza $A\left(\mathrm{H}_{1} \mathrm{~N}_{1}\right)$ pandemic on attitudes and behaviours. In a German study, a minority of healthcare workers stated that the pandemic had influenced their attitude towards vaccination in general [18]. A French study conducted in 2011 and based on self-reported data found no impact of the 2009 influenza pandemic on subsequent seasonal influenza vaccination coverage [19], but according to a later study (carried out in 2012), using data provided by the comprehensive social health insurance database, this coverage had decreased in 2010 [33].

In our study, attitudes towards vaccination and selfreported vaccination behaviours remained strongly correlated after adjustment on the respondents' sociodemographic background (hypothesis (iii) confirmed). Nevertheless, regarding children's MMR vaccination 
status, the relationship was not as strong in 2010 (OR: 1.53 versus 4.20 in 2000 and 5.95 in 2005). As our data are cross-sectional, these relationships should be interpreted cautiously. Indeed, as the proportion of people who endorsed unfavourable attitudes towards vaccination greatly increased in 2010 , we can expect that many of them reported vaccination behaviours (for themselves as for their children) that occurred several years before they changed their mind towards vaccination. Thus their behaviours were not necessarily determined by their attitudinal shift.

Nevertheless, our results showed that attitudes and behaviours are consistent with one another, and one could expect that this attitudinal shift may manifest in vaccination behaviours in coming years. Consequently, trends in children's immunisation should be carefully scrutinised in the next decade, as a significant proportion of future parents ( $27 \%$ of 18 to 24 year-old respondents, $32 \%$ of 25 to 34 year-olds) endorsed unfavourable attitudes towards vaccination in general in 2010.

\section{Conclusions}

In 2010, we observed a dramatic shift in the French population's attitudes towards vaccination in general: unfavourable attitudes have become far more frequent, and the corresponding sociodemographic profile has also changed. Such attitudes and sociodemographic profile should be closely monitored in the future, as this shift may either persist or vanish. Moreover, the 2009 influenza $A\left(\mathrm{H}_{1} \mathrm{~N}_{1}\right)$ pandemic certainly contributed to this upheaval. As attitudes and behaviours are generally consistent one with another, this phenomenon could have a considerable impact on future vaccination coverage. Consequently, health authorities should urgently address this increasing lack of confidence in vaccination.

\section{Acknowledgements}

The French National Institute for Prevention and Health Education (INPES) provided access to the datasets. This research was conducted thanks to a grant from the Infectiopôle Grand Sud (Marseille).

\section{Conflict of interest}

None declared.

\section{Authors' contributions}

CJ, AG and FB conceived and designed the surveys used in this article, PPW and AG conducted statistical analyses, PPW, PV, JR and AC contributed to the interpretation of data and wrote the first draft, and all authors revised the article critically and approved the final version.
References

1. Dingwall R, Hobson-West P. Litigation and the threat to medicine. In: Kelleher D, Gabe J, Williams, editors. Challenging Medicine. 2nd edition. London: Routledge; 2006. p. 40-62.

2. Hobson-West P. The construction of lay resistance to vaccination. In: Shaw I, Kaupinen K, editors. Constructions of health and illness: European perspectives. Aldershot: Ashgate Publishing; 2004. p. 89-106.

3. André FE. Vaccinology: past achievements, present roadblocks and future promises. Vaccine. 2003;21(7-8):593-5. http://dx.doi.org/10.1016/S0264-410X(02)00702-8

4. Black S, Rappuoli R. A crisis of public confidence in vaccines. Sci Transl Med. 2010;2(61):61mr1.

5. Larson HJ, Cooper LZ, Eskola J, Katz SL, Ratzan S. Addressing the vaccine confidence gap. Lancet. 2011;378(9790):526-35. http://dx.doi.org/10.1016/S0140-6736(11)60678-8

6. Harris KM, Maurer J, Kellerman AL. Influenza vaccine - safe, effective, and mistrusted. N Engl J Med. 2010;363(23):2183-5. http://dx.doi.org/10.1056/NEJMp1012333. PMid:21105831.

7. Gangarosa EJ, Galazka AM, Wolfe CR, Phillips LM, Gangarosa RE, Miller E, et al. Impact of anti-vaccine movements on pertussis control: the untold story. Lancet. 1998;351(9099):356-61 http://dx.doi.org/10.1016/S0140-6736(97)04334-1

8. Poland GA, Jacobson RM. The age-old struggle against the antivaccinationists. N Engl J Med. 2011;364(2):97-9.http:// dx.doi.org/10.1056/NEJMp1010594. PMid:21226573.

9. Wolfe RM, Sharp LK, Lipsky MS. Content and design attributes of antivaccination web sites. JAMA. 2002;287(24):3245-8. http://dx.doi.org/10.1001/jama.287.24.3245

10. Muscat M, Bang H, Wohlfahrt J, Glismann S, Mølbak K. Measles in Europe: an epidemiological assessment. Lancet. 2009;373(9661):383-9. http://dx.doi.org/10.1016/ So140-6736(08)61849-8

11. Parent du Châtelet I, Antona D, Freymuth F, Muscat M, Halftermeyer-Zhou F, Maine C, et al. Spotlight on measles 2010: update on the ongoing measles outbreak in France, 2008-2010. Euro Surveill. 2010;15(36):pii=19656. Available from: http://www.eurosurveillance.org/ViewArticle. aspx?Articleld $=19656$

12. Steffen I, Martin R, Lopalco PL. Spotlight on measles 2010: measles elimination in Europe - a new commitment to meet the goal by 2015. Euro Surveill. 2010;15(50):pii=19749. Available from: http://www.eurosurveillance.org/ViewArticle. aspx?Articleld $=19749$

13. Maurer J, Harris KM, Parker A, Lurie N. Does receipt of seasonal influenza vaccine predict intention to receive novel $\mathrm{H}_{1} \mathrm{~N}_{1}$ vaccine: evidence from a nationally representative survey of U.S. adults. Vaccine. 2009;27(42):5732-4. http://dx.doi.org/10.1016/j.vaccine.2009.07.080. PMid:19679219. PMCid:PMC2771376.

14. Schwarzinger M, Flicoteaux R, Cortarenoda S, Obadia Y, Moatti JP. Low acceptability of $\mathrm{A} / \mathrm{H}_{1} \mathrm{~N}_{1}$ pandemic vaccination in French adult population: did public health policy fuel public dissonance? PloSOne. 2010;5(4):e10199. http://dx.doi.org/10.1371/journal.pone.0010199. PMid:20421908. PMCid:PMC2856629.

15. Eastwood K, Durrheim DN, Jones A, Butler M. Acceptance of pandemic $\left(\mathrm{H}_{1} \mathrm{~N}_{1}\right) 2009$ influenza vaccination by the Australian public. Med J Aus. 2010;192(1):33-6. PMid:20047546.

16. Vaux S, Van Cauteren D, Guthman JP, Le Strat Y, Vaillant V, de Valk $\mathrm{H}$, et al. Influenza vaccination coverage against seasonal and pandemic influenza and their determinants in France a cross-sectional survey. BMC Public Health. 2011;11:30. http://dx.doi.org/10.1186/1471-2458-11-30. PMid:21226919. PMCid:PMC3025842.

17. Gidendil CA, Parker AM, Zikmund-Fisher BJ. Trends in risk perceptions and vaccination intentions: a longitudinal study of the first year of the $\mathrm{H}_{1} \mathrm{~N}_{1}$ pandemic. Am J Public Health. 2012;102(4):672-9.

http://dx.doi.org/10.2105/AJPH.2011.300407. PMid:22397349. PMCid:PMC3297965.

18. Brandt C, Rabenau HF, Bornmann S, Gottschalk R, Wicker $\mathrm{S}$. The impact of the 2009 influenza $\mathrm{A}\left(\mathrm{H}_{1} \mathrm{~N}_{1}\right)$ pandemic on attitudes of healthcare workers toward seasonal influenza vaccination 2010/11. Euro Surveill. 2010;16(17): pii =19854. Available from: http://www.eurosurveillance.org/ViewArticle. aspx?Articleld $=19854$

19. Guthman JO, Fonteneau L, Bonmarin I, Lévy-Bruhl D. Influenza vaccination coverage one year after the $A\left(\mathrm{H}_{1} \mathrm{~N}_{1}\right)$ influenza pandemic, France, 2010-2011. Vaccine. 2012;30(6):995-7. http://dx.doi.org/10.1016/j.vaccine.2011.12.011. PMid:22178520.

20. Sherlaw W, Raude J. Why the French did not choose to panic: a dynamic analysis of the public response to the influenza 
pandemic. Sociol Health Illn. 2012;35(2):332-44.

http://dx.doi.org/10.1111/j.1467-9566.2012.01525.x.

PMid:23030815.

21. Raude J, Caille-Brillet al, Setbon M. The 2009 pandemic $\mathrm{H}_{1} \mathrm{~N}_{1}$ influenza vaccination in France: who accepted to receive the vaccine and why? PLoS Curr. 2010;2:RRN1188.

http://dx.doi.org/10.1371/currents.RRN1188. PMid:20972476. PMCid:PMC2957695.

22. Evans M, Stoddart H, Condon L, Freeman E, Grizzell M, Mullen R. Parents' perspectives on the MMR immunisation: a focus group study. Br J Gen Pract. 2001;51(472):904-10. PMid:11761204. PMCid:PMC1314147.

23. Poltorak M, Leach M, Fairhead J, Cassell J. 'MMR talk' and vaccination choices: an ethnographic study in Brighton. Soc Sci Med. 2005;61(3):709-19. http://dx.doi.org/10.1016/j.socscimed.2004.12.014 PMid:15899328.

24. Blume S. Anti-vaccination movements and their interpretations. Soc Sci Med. 2006;62(3):628-42. http://dx.doi.org/10.1016/j.socscimed.2005.06.020. PMid:16039769.

25. Smith MJ, Marshall GS. Navigating parental vaccine hesitancy. Pediatr Ann. 2010;39(8):476-82

http://dx.doi.org/10.3928/00904481-20100726-05.

PMid:20704143.

26. Velan B, Kaplan G, Ziv A, Boyko V, Lerner-Geva L. Major motives in non-acceptance of $\mathrm{A} / \mathrm{H}_{1} \mathrm{~N}_{1}$ flu vaccination: the weight of rational assessment. Vaccine. 2001;29(6):1173-9. http://dx.doi.org/10.1016/j.vaccine.2010.12.006. PMid:21167862.

27. Slovic P. The perception of risk. London: Earthscan; 2000.

28. Nougairède A, Lagier JC, Ninove L, Sartor C, Badiaga S, Bothelo $E$, et al. Likely correlation between sources of information and acceptability of $A / H_{1} N_{1}$ swine-origin influenza virus vaccine in Marseille, France. PloS One. 2010;5(6):e11292.

http://dx.doi.org/10.1371/journal.pone.0011292.

PMid:20593024. PMCid:PMC 2892508.

29. Walter D, Böhmer MM, Reiter S, Krause G, Wichmann O. Risk perception and information-seeking behaviour during the 2009/10 influenza $A\left(\mathrm{H}_{1} \mathrm{~N}_{1}\right)$ pdmog pandemic in Germany. Euro Surveill. 2012;17(13):pii=20131. Available from: http://www. eurosurveillance.org/ViewArticle.aspx?Articleld=20131

30. Winston CA, Wortley PM, Lees KA. Factors associated with vaccination of medicare beneficiaries in five U.S. communities: results from the racial and ethnic adult disparities in immunization initiative survey, 2003. J Am Geriatr Assoc. 2006;54(2):303-10.

http://dx.doi.org/10.1111/j.1532-5415.2005.00585.x. PMid:16460383.

31. Peretti-Watel P, Moatti JP. Le principe de prévention: Le culte de la santé et ses dérives. [The principle of prevention: The cult of health and its excesses]. Paris: Seuil; 2009. French.

32. Semenza JC, Suk JE, Tsolova S. Social determinants of infectious diseases: a public health priority. Euro Surveill. 2010;15(27):pii=19608. Available from: http://www. eurosurveillance.org/ViewArticle.aspx?Articleld $=19608$

33. Guthman JP, Fonteneau L, Lévy-Bruhl D. Mesure de la couverture vaccinale en France: sources et données actuelles. [Assessment of immunisation coverage in France: data sources and current figures]. Saint Maurice: Institut de Veille Sanitaire; 2012. 98 p. French. 